\title{
The influence of selected factors on the effectiveness of rhGH replacement therapy in children with growth hormone deficiency
}

\author{
${ }^{1}$ Agnieszka Zubkiewicz-Kucharska, ${ }^{2}$ Wioletta Lasota, ${ }^{2}$ Urszula Tumilewicz, ${ }^{2}$ Agnieszka Matula, ${ }^{1}$ Monika Seifert, \\ ${ }^{1}$ Anna Noczyńska
}

${ }^{1}$ Katedra i Klinika Endokrynologii i Diabetologii Wieku Rozwojowego, Uniwersytet Medyczny we Wrocławiu

${ }^{2}$ Studenckie Koło Naukowe przy Katedrze i Klinice Endokrynologii Wieku Rozwojowego, Uniwersytet Medyczny we Wrocławiu

Adres do korespondencji:

Agnieszka Zubkiewicz-Kucharska, Katedra i Klinika Endokrynologii i Diabetologii Wieku Rozwojowego, Uniwersytet Medyczny we Wrocławiu, ul. Chałubińskiego 2a, 50-368 Wrocław, agnieszka.zubkiewicz-kucharska@umed.wroc.pl

Słowa kluczowe: niedobór wzrostu, somatotropinowa niedoczynność przysadki, tempo wzrastania, skuteczność terapii, czynniki prognostyczne Key words: short stature, growth hormone deficiency, height velocity, therapy effectiveness, prognostic factors

\section{STRESZCZENIE/ABSTRACT}

\begin{abstract}
Wstęp. Somatotropinowa niedoczynność przysadki (SNP) jest leczona za pomocą biosyntetycznej somatotropiny (rhGH). Proces wzrastania warunkowany jest przez wiele czynników, dlatego efekt terapii u dziecka może być różny. Do chwili obecnej nie ustalono dokładnych czynników predykcyjnych tempa wzrastania. Cel pracy. Celem pracy była ocena tempa wzrastania w pierwszym i drugim roku leczenia rhGH u dzieci z SNP oraz analiza wpływu wybranych czynników na skuteczność terapii. Material i metody. Do badania zakwalifikowano 411 dzieci z SNP leczonych w Klinice Endokrynologii i Diabetologii Wieku Rozwojowego we Wrocławiu. Tempo wzrastania (HV, HVSDS) oraz

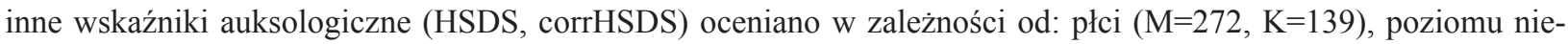
doboru GH (całkowity N=131, częściowy N=266) i etapu dojrzewania płciowego w momencie rozpoczęcia terapii

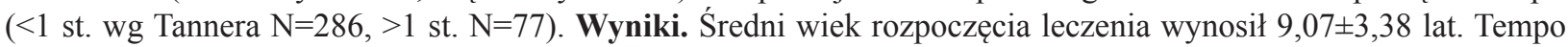
wzrastania było lepsze w pierwszym roku terapii, a wzrost pacjentów w tym czasie znacznie zbliżył się do średniej wzrostu dla płci i wieku . Odnotowano większe tempo wzrastania w pierwszym roku terapii w grupie dzieci z całkowitym niedoborem GH. W badanej grupie moment rozpoczęcia leczenia (okres prepubetarlny vs. pubertalny) ani płeć nie wpływały na tempo wzrastania w pierwszych dwóch latach leczenia. Przyrost wzrostu był znamienny u dzieci w okresie prepubertalnym. Wnioski. Lepszą odpowiedź na leczenie rhGH (największe tempo wzrastania i przyrost wzrostu) zaobserwowano w pierwszym roku leczenia. Większą skuteczność terapii rhGH stwierdzono u pacjentów z całkowitym niedoborem GH oraz bez cech dojrzewania płciowego. Endokrynol. Ped. 13/2014;4(49):19-26.
\end{abstract}


Introduction. Growth Hormone Deficiency (GHD) is treated with recombinant human growth hormone (rhGH). The process of growth is conditioned by several elements, therefore the effects of therapy vary between patients. At the moment, no precise prediction methods have been established. Aims. The aim of this paper was to evaluate height velocity in the 1st and the 2nd year of rhGH therapy in children with GHD. Moreover, selected factors were analyzed in terms of their influence on the efficacy of the treatment. Material and methods. 411 children with GHD treated in the Department of Endocrinology and Diabetology for Children and Adolescents in Wrocław were qualified for the study. Height velocity (HV, HVSDS) and other auxiological parameters (HSDS, corrHSDS) were assessed depending on the: gender $(\mathrm{M}=272, \mathrm{~K}=139)$, level of $\mathrm{GH}$ deficiency (total $\mathrm{N}=131$, partial $\mathrm{N}=266$ ) and stage of puberty at the beginning of therapy ( $1^{\text {st }}$ degree acc. to Tanner $\left.\mathrm{N}=286,>1^{\text {st }} \mathrm{N}=77\right)$. Results. The average age at the beginning of therapy was 9,07 $\pm 3,38$ years. Height velocity was better in the 1 st year of treatmentand patients' height at this time got closer to average for the age and sex. The results indicated faster height velocity in the 1 st year of treatment among children with total GHD . Pubertal status at the outset of therapy as well as sex did not influence height velocity in the first two years of treatment. However the increase in patients' height was proved to be significantly better among children in prepubertal period. Conclusions. The best response to the rhGH treatment (the greatest height velocity and the best increase of the growth) is observed in the 1st year of therapy. RhGH treatment proved to be more effective for patients with total GH deficiency and no signs of sexual maturation. Pediatr. Endocrinol. 13/2014;4(49):19-26.

\section{Wstęp}

Somatotropinowa niedoczynność przysadki (SNP, GHD, growth hormone deficiency) występuje w populacji dziecięcej z częstością od 1/5000 do 1/15000 [1]. Przyczyną wrodzonej SNP mogą być genetycznie uwarunkowane defekty syntezy i wydzielania GH w przysadce oraz zmiany organiczne w zakresie mózgowia. U ponad $1 / 3$ pacjentów pediatrycznych stwierdza się nabytą SNP, której przyczyną najczęściej są choroby ośrodkowego układu nerwowego, w tym urazy i nowotwory oraz powikłania prowadzonych terapii [2].

SNP jest podstawowym, obok zespołu Turnera, przewlekłej niewydolności nerek oraz zespołu Prader-Williego, wskazaniem do leczenia substytucyjnego hormonem wzrostu $[1,3]$. Leczenie polega na podaży biosyntetycznego rekombinowanego ludzkiego hormonu wzrostu (rhGH), który wywołuje efekty metaboliczne identyczne do naturalnego hormonu wzrostu [4]. Celem leczenia, a także miarą jego skuteczności jest poprawa tempa wzrastania (HV, height velocity), a także poprawa pozycji centylowej wzrostu (HSDS, height SDS) [5].

Proces wzrastania, oprócz prawidłowego poziomu GH, uwarunkowany jest wieloma innymi czynnikami. Dotychczas nie ustalono dokładnych czynników predykcyjnych, co nie pozwala na jednoznaczną ocenę efektów terapii rhGH [6].

\section{Cel}

Celem pracy było porównanie tempa wzrastania pacjentów z SNP w pierwszym i drugim roku leczenia rhGH oraz ocena wpływu na skuteczność tera- pii takich czynników, jak: płeć, poziom niedoboru wzrostu i stadium dojrzewania płciowego.

\section{Materiały i metody}

Do badania zakwalifikowano 411 pacjentów Kliniki Endokrynologii i Diabetologii Wieku rozwojowego we Wrocławiu, którzy w latach 1995-2013 otrzymywali rhGH z powodu SNP. Pacjenci zostali zakwalifikowani do leczenia na podstawie wytycznych programu terapeutycznego „Leczenie niskorosłych dzieci z somatotropinową niedoczynnością przysadki" [3]. Średni wiek rozpoczęcia terapii to $9,07 \pm 3,38$ lat, a stosowana dawka rhGH wynosiła $0,023 \mathrm{mg} / \mathrm{kg} / \mathrm{dzien}$.

Przeanalizowano dane $\mathrm{N}=139$ dziewcząt oraz $\mathrm{N}=272$ chłopców. Ze względu na stopień dojrzewania płciowego pacjentów podzielono na dwie grupy: grupe I - dzieci bez cech dojrzewania płciowego $\mathrm{N}=286$, oraz grupę II - dzieci z obecnymi cechami dojrzewania $\mathrm{N}=77$. Dzieci, które $\mathrm{w}$ ani jednym z przeprowadzonych testów stymulacyjnych przed rozpoczęciem terapii nie osiągnęly poziomu hormonu wzrostu ponad $5 \mathrm{ng} / \mathrm{ml}$, zostały włączone do grupy $\mathrm{z}$ całkowitym poziomem niedoboru wzrostu (cSNP) $\mathrm{N}=131$, pozostałe znalazły się w grupie z częściowym niedoborem hormonu wzrostu (czSNP) N=266 (tabela 1).

W poszczególnych grupach porównano następujące wskaźniki auksologiczne [5]:

1. Wskaźnik odchylenia standardowego wzrostu (height SDS):

$$
H S D S=\frac{\text { wzrost dziecka }- \text { wzrost } 50 \mathrm{c}}{0,5 \mathrm{x}(\text { wzrost } 50 \mathrm{c}-\text { wzrost } 3 \mathrm{c})}
$$


2. Tempo wzrastania (height velocity): $H V\left[\frac{\mathrm{cm}}{\mathrm{rok}}\right]$ obliczone na podstawie przyrostu wysokości ciała w okresie 6-12 miesięcznej obserwacji, a także wskaźnik odchylenia standardowego tempa wzrastania:

$H V S D S=\frac{H V-H V \text { średnie w populacji referencyjnej }}{H V S D}$

Odchylenie aktualnego wzrostu od wzrostu docelowego (target height, TH): skorygowany HSDS (corrHSDS: corrHSDS $=h S D S-T H S D S$ ).

Do opracowania danych wykorzystano siatki centylowe dzieci warszawskich z roku 2001 oraz tabele tempa wzrastania opracowane przez Pradera i wsp. $[7,8]$.

W analizie statystycznej wykorzystano testy: Shapiro-Wilka do zbadania typu rozkładu, a następnie w celu sprawdzenia istotności statystycznej różnic analizowanych parametrów zastosowano testy U Manna-Whitneya, ANOVA oraz test $\mathrm{t}$ dla par. Analizę statystyczną przeprowadzono z wykorzystaniem programu Statistica 10.0.

\section{Wyniki}

Tempo wzrastania w pierwszym i drugim roku terapii były istotnie większe w porównaniu $\mathrm{z}$ tempem wzrastania obserwowanym przed rozpoczęciem leczenia (HVSDS0: $-1,86 \pm 3,6$ vs. HVSDS1: $3,4 \pm 2,85 ; \mathrm{p}<0,0001$ oraz HVSDS0: $-1,86 \pm 3,6$ vs. HVSDS2: 2,3 $\pm 3,2 \mathrm{p}<0,0001)$.

Porównując wartości tempa wzrastania z okresu dwu lat leczenia, wykazano znamienną przewagę w pierwszym roku terapii (HVSDS1: 3,4 2 2,85 vs. HVSDS2: 2,3 $\pm 3,2 \mathrm{p}<0,001)$.

Wzrost pacjentów (wyrażony za pomocą wartości wskaźnika odchylenia standardowego, HSDS) w tym czasie znacznie zbliżył się do wartości populacyjnych, odpowiednich dla płci i wieku dziecka (HSDS1: $-1,2 \pm 1,0$ vs. HSDS2: 0,4 $\pm 1,3 ; \mathrm{p}<0,001$, corr HSDS1: $-0,34 \pm 1,1$ vs. corr HSDS2: 1,15 $\pm 1,3 ; \mathrm{p}<0,001)$. Średni przyrost wzrostu ( $\triangle$ HSDS) w pierwszym roku wy-

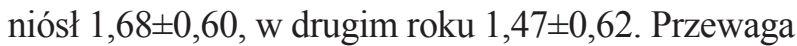
odpowiedzi wzrostowej podczas pierwszych 12 miesięcy była znacząco wyższa $(\mathrm{p}<0,001)$ w porównaniu

Tabela I. Liczebność oraz średni wiek rozpoczęcia terapii analizowanych pacjentów z uwzględnieniem podziału na poszczególne grupy

Table I. Group size and mean age of rhGH therapy initiation in analyzed patients

\begin{tabular}{|c|c|c|c|c|c|}
\hline \multicolumn{6}{|c|}{ Liczba pacjentów ogółem: 411} \\
\hline \multicolumn{2}{|c|}{ Płeć } & \multicolumn{2}{|c|}{ Dojrzewanie } & \multicolumn{2}{|c|}{ Poziom niedoboru GH } \\
\hline K & M & 1 st. Tanner & $>1$ st. Tanner & całkowity & częściowy \\
\hline 139 & 272 & 286 & 77 & 131 & 266 \\
\hline \multicolumn{6}{|c|}{$\begin{array}{l}\text { Wiek rozpoczęcia terapii ogółem: } \\
\qquad 9,07 \pm 3,38 \text { lat }\end{array}$} \\
\hline $\begin{array}{c}8,59 \\
\pm 3,11\end{array}$ & $\begin{array}{c}9,31 \\
\pm 3,49\end{array}$ & $\begin{array}{l}8,06 \\
\pm 3,34\end{array}$ & $\begin{array}{l}13,54 \\
\pm 1,76\end{array}$ & $\begin{array}{c}8,84 \\
\pm 3,53\end{array}$ & $\begin{array}{c}9,23 \\
\pm 3,34\end{array}$ \\
\hline \multicolumn{2}{|c|}{$p>0,05$} & \multicolumn{2}{|c|}{$p<0,00001$} & \multicolumn{2}{|c|}{$p>0,05$} \\
\hline
\end{tabular}

Tabela II. Wybrane dane auksologiczne po 1 roku i po 2 latach terapii

Table II. Selected auxological parameters in the first and second year of rhGH therapy

\begin{tabular}{|c|c|c|c|}
\hline Czas terapii & 1 Rok & 2 rok & $p$ \\
\hline Hvsds & $3,43 \pm 2,85$ & $2,29 \pm 3,20$ & $1,86 \mathrm{e}-08$ \\
\hline Hsds & $-1,15 \pm 1,01$ & $0,39 \pm 1,31$ & $1,95 \mathrm{e}-47$ \\
\hline hsds & $1,68 \pm 0,60$ & $1,47 \pm 0,62$ & $5,64 \mathrm{e}-07$ \\
corrhsds & $-0,34 \pm 1,13$ & $1,15 \pm 1,31$ & $2,94 \mathrm{e}-28$ \\
\hline
\end{tabular}


z drugim rokiem leczenia. Powyższe wyniki zestawiono w tabeli II i na rycinie 1 .

W momencie rozpoczęcia terapii dziewczynki były nieznacznie $(\mathrm{p}>0,05)$ młodsze i niższe od chłopców. W badanej grupie płeć nie wpływała na tempo wzrastania i poprawę tempa wzrostu w latach objętych analizą ( $p>0,05)$. Dokładne wyniki przedstawiono w tabeli III.

Na początku terapii GH średni wzrost pacjentów (HSDS) wynosił w grupie cSNP -2,94 $\pm 1,06$, a w grupie czSNP $-2,699 \pm 1,06$, $(\mathrm{p}>0,05)$. Po pierwszym roku leczenia $\mathrm{w}$ grupie cSNP stwierdzono znamienną poprawę wzrostu i istotne zbliżenie się wartości do średniej dla płci i wieku ( $\triangle$ HSDS $1,86 \pm 0,75$ vs. $1,58 \pm 0,49 ; \mathrm{p}=0,0035$ ). Ponadto $\mathrm{w}$ tym okresie $\mathrm{u}$ pacjentów z całkowitym niedoborem hormonu odnotowano istotnie statystycznie wyższe tempo wzrastania (HVSDS: 4,1 $\pm 3,1$ vs $3,1 \pm 2,7 ; \mathrm{p}=0,002$ ). Wyniki przedstawiają tabela IV i rycina 2.

Średni wzrost przed leczeniem u dzieci nie zależał od stopnia dojrzewania płciowego. W całym czasie objętym analizą (tzn. w ciągu pierwszych dwóch lat leczenia) przyrost wzrostu okazał się znamiennie większy u pacjentów w okresie prepubertalnym (Tanner 1 st. vs Tanner $>1$ st.: $\triangle$ HSDS1: $1,75 \pm 0,6$ vs $1,36 \pm 0,3 ; p<0.001 ; \Delta$ HSDS2: $1,55 \pm 0,6$ vs $1,08 \pm 0,3 ; \mathrm{p}<0,001)$. Jednocześnie nie wykazano wpływu momentu rozpoczęcia terapii (okres prepubertalny vs pubertalny) na tempo wzrastania w pierwszych dwóch latach leczenia. Wyniki zestawiono $\mathrm{w}$ tabeli $\mathrm{V}$.

\section{Dyskusja}

Uzyskanie prawidłowej końcowej wysokości ciała to główny cel terapii hormonem wzrostu u dzieci z SNP. Odpowiedź na leczenie jest zmienna osobniczo i zależna od wielu wciąż niesprecyzowanych czynników predykcyjnych [6]. Ich dokładna znajomość pozwoliłaby prognozować indywidualną odpowiedź wzrostową pacjentów przed rozpoczęciem lub $\mathrm{w}$ pierwszych miesiącach terapii, umożliwiając tym samym personalizację i optymalizację prowadzonego leczenia.

Liczne publikacje oparte na analizach dużych grup pacjentów z SNP podczas leczenia hormonem wzrostu podkreślają, że odpowiedź wzrostowa jest największa w pierwszym roku terapii $[6,9,10]$. Wyniki prowadzonych przez nas obserwacji są zbieżne. Wykazały bowiem znamienną przewagę zarówno tempa wzrastania, jak i przyrostu wzrostu w pierwszym roku leczenia w porównaniu z wynikami uzyskanymi w drugim roku terapii rhGH. Pozwala to przypuszczać, że czas ten jako okres „nadrabiania” niedoboru wysokości może mieć decydujący wpływ na końcowy efekt terapii.

Wyniki naszych obserwacji nie wskazały na wpływ płci na efekt terapii. Dziewczynki i chłopcy w podobnym stopniu wyrównywali niedobór wzrostu, dlatego można przypuszczać, że inne czynniki mogą decydować o tempie wzrastania.

Najlepszy efekt leczenia hormonem wzrostu obserwuje się u pacjentów, u których wykazano

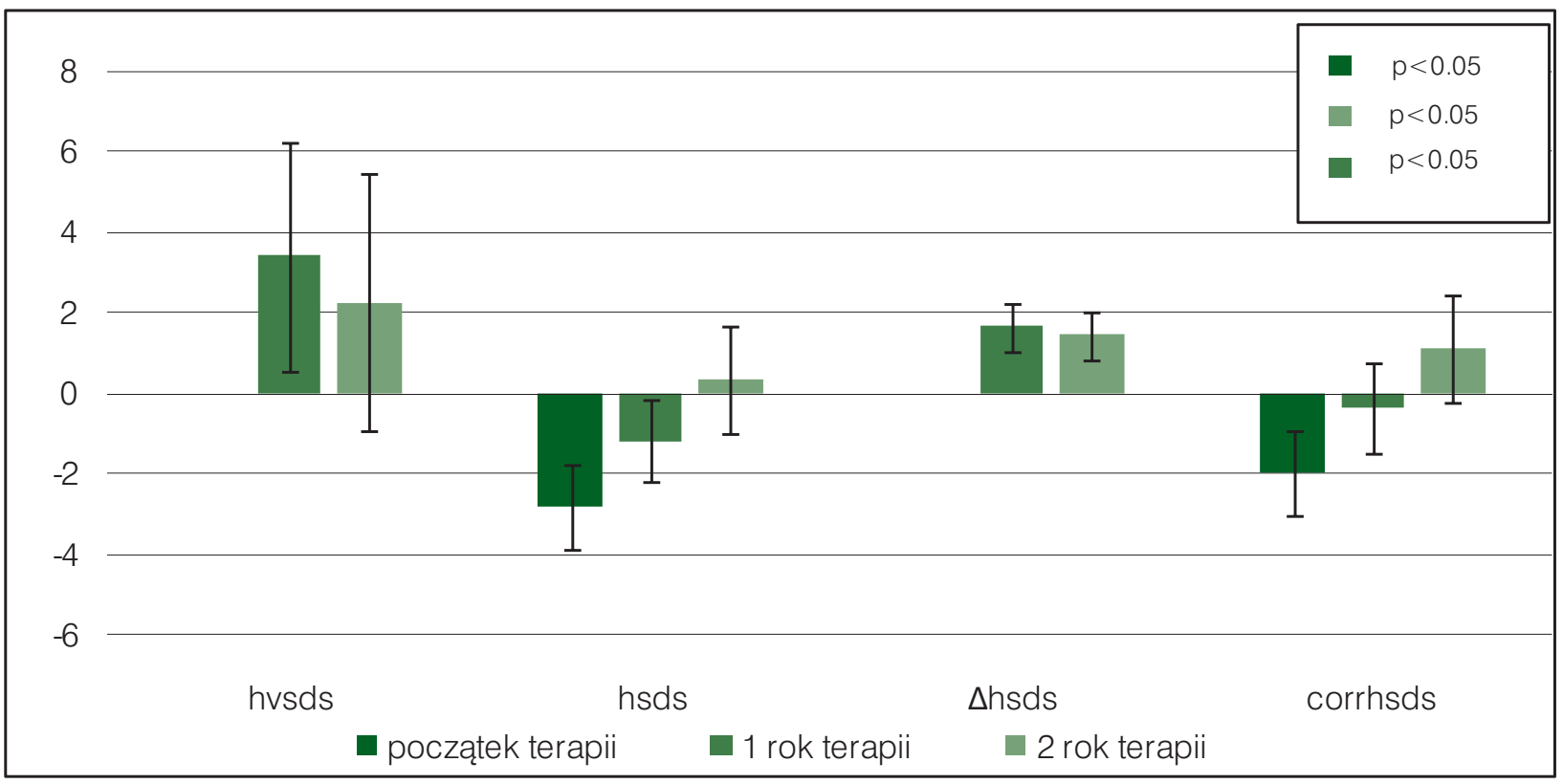

Ryc. 1. Porównanie efektów terapii po 1 i po 2 latach terapii

Fig. 1. rhGH Therapy effectiveness after first and second year of treatment 
Tabela III. Wybrane dane auksologiczne u dziewcząt lub chłopców w momencie rozpoczęcia, po 1 roku i po 2 latach terapii Table III. Selected auxological parameters in boys and girls before the treatment, in the first and second year of rhGH therapy

\begin{tabular}{|c|c|c|c|}
\hline Grupa & dziewczynki & chtopcy & $p$ \\
\hline \multicolumn{4}{|c|}{ Moment rozpoczęcia terapii } \\
\hline Wiek & $8,59 \pm 3,11$ & $9,31 \pm 3,49$ & 0,29 \\
\hline HSDS & $-2,91 \pm 0,93$ & $-2,73 \pm 1,12$ & 0,12 \\
\hline corrHSDS & $-1,98 \pm 1,14$ & $-1,95 \pm 1,01$ & 0,59 \\
\hline \multicolumn{4}{|c|}{ Po 1 roku terapii } \\
\hline HVSDS & $3,50 \pm 2,74$ & $3,39 \pm 2,90$ & 0,98 \\
\hline HSDS & $-1,26 \pm 1,15$ & $-1,10 \pm 0,94$ & 0,28 \\
\hline$\Delta \mathrm{HSDS}$ & $1,71 \pm 0,63$ & $1,66 \pm 0,58$ & 0,50 \\
\hline corrHSDS & $-0,40 \pm 1,25$ & $-0,31 \pm 1,08$ & 0,93 \\
\hline \multicolumn{4}{|c|}{ Po 2 latach terapii } \\
\hline HVSDS & $2,27 \pm 3,52$ & $2,30 \pm 3,01$ & 0,58 \\
\hline HSDS & $0,29 \pm 1,51$ & $0,44 \pm 1,19$ & 0,34 \\
\hline$\Delta \mathrm{HSDS}$ & $1,51 \pm 0,76$ & $1,45 \pm 0,52$ & 0,86 \\
\hline corrHSDS & $0,95 \pm 1,49$ & $1,24 \pm 1,22$ & 0,29 \\
\hline
\end{tabular}

Tabela IV. Wybrane dane auksologiczne u dzieci w grupie z całkowitym lub częściowym niedoborem hormonu wzrostu w momencie rozpoczęcia, po 1 roku i po 2 latach terapii

Table IV. Selected auxological parameters in patients with complete and partial growth hormone deficiency before the treatment, in the first and second year of rhGH therapy

\begin{tabular}{|c|c|c|c|}
\hline \multicolumn{1}{|c|}{ Grupa } & Całkowity niedobór GH & Częściowy niedobór GH & $p$ \\
\hline Wiek & $8,84 \pm 3,53$ & $9,23 \pm 3,34$ & \\
HSDS & $-2,94 \pm 1,06$ & $-2,699 \pm 1,06$ & 0,16 \\
CorrHSDS & $-2,21 \pm 1,22$ & $-1,857 \pm 0,95$ & 0,084 \\
\hline HVSDS & $4,1 \pm 3,1$ & $3,1 \pm 2,7$ & 0,0023 \\
HSDS & $-1,10 \pm 1,2$ & $-1,17 \pm 0,92$ & 0,37 \\
AHSDS & $1,86 \pm 0,75$ & $1,58 \pm 0,49$ & 0,0035 \\
corrHSDS & $-0,46 \pm 1,32$ & $-0,29 \pm 1,05$ & 0,80 \\
& \multicolumn{2}{|c|}{ Po 2 latach terapii } & 0,821 \\
HVSDS & $2,69 \pm 3,9$ & $2,24 \pm 2,85$ & 0,31 \\
HSDS & $0,55 \pm 1,6$ & $0,34 \pm 1,17$ & 0,29 \\
\hline HHSDS & $1,6 \pm 0,84$ & $1,42 \pm 0,49$ & 0,65 \\
\hline
\end{tabular}




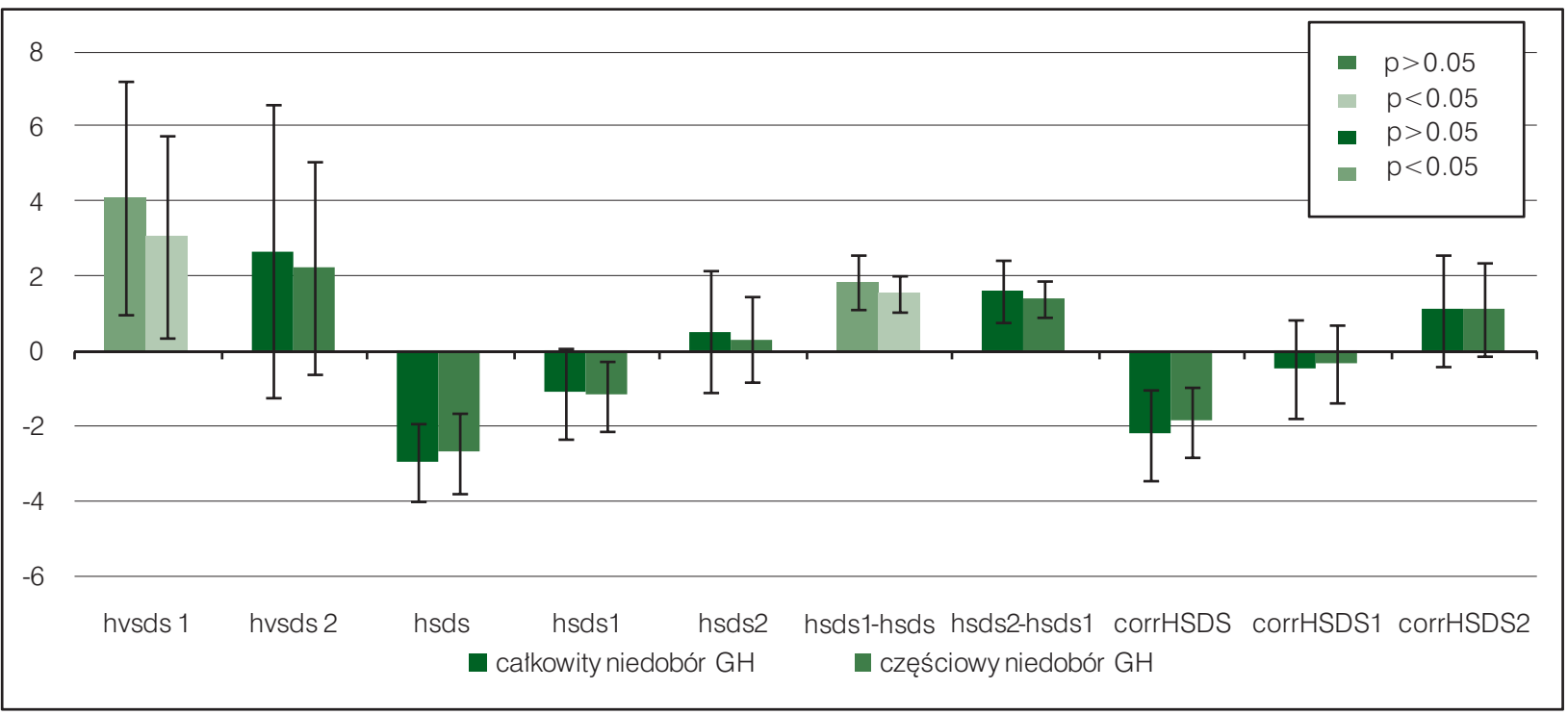

Ryc. 2. Wpływ poziomu niedoboru hormonu wzrostu na wybrane wskaźniki auksologiczne

Fig. 2. Selected auxological parameters according to degree of growth hormone deficiency

Tabela V. Wybrane dane auksologiczne u dzieci w okresie prepubertalnym lub pubertalnym w momencie rozpoczęcia, po 1 roku i po 2 latach terapii

Table V. Selected auxological parameters in patients in prepubertal and pubertal age before the treatment, in the first and second year of rhGH therapy

\begin{tabular}{|c|c|c|c|}
\hline Grupa & 1 st. Tannera & $>1$ st. Tannera & $p$ \\
\hline \multicolumn{4}{|c|}{ Moment rozpoczęcia terapii } \\
\hline Wiek & $8,06 \pm 3,38$ & $13,54 \pm 1,76$ & \\
\hline HSDS & $-2,8 \pm 1,13$ & $-2,7 \pm 0,76$ & 0,26 \\
\hline corrHSDS & $-1,97 \pm 1,05$ & $1,83 \pm 0,99$ & 0,44 \\
\hline \multicolumn{4}{|c|}{ Po 1 roku terapii } \\
\hline HVSDS & $3,45 \pm 2,8$ & $3,697 \pm 3,35$ & 0,81 \\
\hline HSDS & $-1,12 \pm 1,05$ & $-1,36 \pm 0,79$ & 0,01 \\
\hline$\Delta \mathrm{HSDS}$ & $1,75 \pm 0,63372$ & $1,36 \pm 0,31$ & $6,09 \mathrm{e}-07$ \\
\hline corrHSDS & $-0,26 \pm 1,17$ & $-0,56 \pm 1,00$ & 0,02 \\
\hline \multicolumn{4}{|c|}{ Po 2 latach terapii } \\
\hline HVSDS & $2,43 \pm 3,26$ & $2,02 \pm 3,42$ & 0,55 \\
\hline HSDS & $0,498 \pm 1,34$ & $-0,14 \pm 0,63$ & 0,0004 \\
\hline$\Delta \mathrm{HSDS}$ & $1,55 \pm 0,64$ & $1,08 \pm 0,32$ & $6,99 \mathrm{e}-07$ \\
\hline corrHSDS & $1,296 \pm 1,36$ & $0,57 \pm 0,92$ & 0,0009 \\
\hline
\end{tabular}


całkowity niedobór $\mathrm{GH}$, co potwierdzają dotychczasowe publikacje dotyczące terapii dzieci z SNP. W latach 1993 i 1999 zaproponowano modele matematyczne predykcji odpowiedzi na leczenie hormonem wzrostu, w których czynnikami o największej wartości prognostycznej okazały się różnica pomiędzy wzrostem docelowym a wysokością ciała przed rozpoczęciem leczenia [11] oraz logarytmiczna wartość maksymalnego wyrzutu hormonu wzrostu w testach stymulacyjnych [12]. Potwierdzili to także inni autorzy $[13,14]$, wykazując, że skuteczność leczenia jest znamiennie wyższa u pacjentów z ciężkim niedoborem hormonu wzrostu i bardzo niskim wydzielaniem GH w testach stymulacyjnych. W naszych badaniach w pierwszym roku leczenia stwierdzono istotnie wyższe tempo wzrastania i znamienną poprawę wzrostu $\mathrm{w}$ grupie pacjentów z całkowitą SNP.

Średni wzrost przed leczeniem w badanej przez nas grupie nie zależał od stopnia dojrzewania płciowego. W całym okresie objętym analizą przyrost wzrostu okazał się jednak wyższy u pacjentów w okresie prepubertalnym, natomiast obecność cech dojrzewania płciowego ( $>1$ st. wg Tannera) nie miała wpływu na tempo wzrastania. W badaniach Kosteckiej i wsp. porównanie efektu terapeutycznego u dzieci w różnych fazach dojrzewania płciowego wykazało najlepsze tempo wzrostu u pacjentów, u których leczenie rozpoczęto przed 6 rokiem życia, co może wynikać z dłuższego okresu leczenia u tych pacjentów, a także większego potencjału chrząstki wzrostowej [15].
Ze względu na fakt, iż pacjenci poddani analizie są nadal leczeni hormonem wzrostu, nie oceniano wzrostu końcowego badanych dzieci.

Substytucja rhGH jest skutecznym leczeniem dzieci z SNP. Potwierdza to przede wszystkim szybka i znaczna odpowiedź wzrostowa. Najlepsze efekty obserwuje się już po pierwszych 12 miesiącach terapii. W celu jak najpełniejszego wykorzystania efektu terapeutycznego podawanego hormonu i uzyskania zadowalających efektów leczenie powinno zostać wdrożone możliwie wcześnie. Z tego względu tak ważna jest czujność pediatrów i lekarzy pierwszego kontaktu, do których obowiązku należy wykonanie okresowych pomiarów wzrostu i wagi dzieci w 2, 4, 6 i 10 roku życia oraz reakcja na stany niepokojące. Badania wykazały, że dzieci młodsze, bez cech dojrzewania płciowego, z głębszym niedoborem hormonu wzrostu i gorszymi wynikami testów stymulacyjnych przed rozpoczęciem terapii, uzyskują lepszy wynik leczenia rhGH, co pozwala traktować wymienione cechy jako pozytywne czynniki predykcyjne [15].

\section{Wnioski}

Lepszą odpowiedź na leczenie rhGH (największe tempo wzrastania i przyrost wzrostu) zaobserwowano w pierwszym roku leczenia.

Większą skuteczność terapii rhGH stwierdzono u pacjentów z całkowitym niedoborem GH oraz bez cech dojrzewania płciowego.

\section{REFERENCES/PIŚMIENNICTWO}

[1] Mysłek-Prucnal M., Bieniasz J., Noczyńska A.: Obserwacja dzieci z całkowitą i częściową somatotropinową niedoczynnością przysadki (SNP) leczonych hormonem wzrostu (GH). Pediatric Endocrinology, Diabetes and Metabolism, 2010:16, 1, 33-38.

[2] Hilczer M., Lewiński A.: Wskazania do leczenia hormonem wzrostu u dzieci i dorosłych. Przegląd Pediatryczny, 2004:34, 170-175.

[3] http://www2.mz.gov.pl/wwwfiles/ma struktura/docs/ogolnopolski program niedoborwzrostu.doc

[4] http://ec.europa.eu/health/documents/community-register/2006/2006042411230/anx_11230_pl.pdf

[5] Smyczyńska J., Lewiński A., Hilczer M.: Wskaźniki auksologiczne przydatne w diagnošstyce dżieci z niedoborem wzrostu i w monitorowaniu skuteczności ich leczenia. Endokrynol. Ped., 2013:2(43), 51-56.

[6] Witkowska-Sędek E., Kucharska A., Pyrżak B., Majcher A.: Ocena odpowiedzi wzrostowej w pierwszym roku leczenia hormonem wzrostu u dzieci z somatotropinową niedoczynnością przysadki (SNP) w zależności od wybranych parametrów auksologicznych i biochemicznych. Endokrynol. Pediatr., 2009:vol. 8, nr 3(28), 31-37.

[7] Palczewska I., Niedźwiedzka Z. Wskaźniki rozwoju somatycznego dzieci i młodzieży warszawskiej. Med. Wieku Rozwoj., 2001:5 (1-2, supl).

[8] Prader A, Largo RH, Molinari L, Issler C.: Physical growth of Swiss children from birth to 20 years of age. First Zurich longitudinal study of growth and development. Helv. Paediatr. Acta. Suppl., 1989 Jun:52, 1-125.

[9] Kurpal- Szczyrska M., Dorant B., Kamińska H. et al.: Ocena wzrostu końcowego pacjentów z somatotropinową niedoczynnością przysadki leczonych hormonem wzrostu. Endokrynologia, Diabetologia i Choroby Przemiany Materii Wieku Rozwojowego, 2006:12, 31-34. 
[10] Cutfield W., Lindberg A., Chatelain P. et al.: Final height following growth hormone treatment of idiopathic hormone deficiency in KIGS. Growth Hormone Therapy in KIGS. 10 years' experience. (red.) M.B. Ranke, Wilton P. Johann Ambrosius Barth Verlag, Lepizig-Heidelberg 1999, 93-109.

[11] Ranke M. B., Guilbaud 0., Lindberg A., Cole T.: Prediction of the growth response in children with various growth disorders treated with growth hormone: analyses of data from the Kabi Pharmacia International Growth Study. International Board of the Kabi Pharmacia International Growth Study. Acta Paediatr., 1993: 391 (supl), 82-88.

[12] Ranke M. B., Lindberg A., Chatelain P., Wilton P., Cuttield W. et al.: On behalf of the KIGS International Board Derivation and Validation of a mathematical Model for Predicting the Response to Exogenous Recombinant Human Growth Hormone (GH) in Prepubertal Children with Idiopathic GH Deficiency. J. Clin. Endocrinol. Metab., 1999:84, 4, 1174-1183.

[13] Hilczer M.: Ocena czynników prognostycznych skuteczności leczenia hormonem wzrostu u dzieci z somatotropinową niedoczynnością przysadki. Clin. Exp. Med., 2006:47, 7-44.

[14] Cacciari E., Cicognani A., Pirazzoli P. et al.: Final height of patients treated for isolated GH deficiency; examinations of 83 patients. Eur. J. Endocrinol., 1997:137, 53-60.

[15] Kostecka L., Wąsikowa R.: Retrospektywna kompleksowa ocean efektów leczenia dzieci z somatotropinową niedoczynnością przysadki. Endokrynologia, Diabetologia i Choroby Przemiany Materii Wieku Rozwojowego, 2005:11, 161-169. 